\title{
A Coordenação nas Políticas Sociais Activas o Caso do Rendimento Mínimo Garantido em Portugal
}

Ana Cardoso *

\begin{abstract}
$\mathrm{R}$ Lesumo: A criação do Rendimento Mínimo Garantido representa uma inovação no contexto da acção social em Portugal. A legislação sobre o Rendimento Mínimo Garantido determina a criação de Comissões Locais de Acompanhamento (CLA), o que contribui para transformar um certo modo de fazer parcerias a nível local. De facto, com a criação das CLA, assiste-se à transformação de uma lógica "do topo para a base" numa lógica "da base para o topo". Contudo, certas coisas não mudam apenas "por decreto", entre as quais a dimensão da coordenação. Isto significa que: a coordenação é um processo; a coordenação requer tempo (tempo para se constituir e tempo para gerar impactes); a coordenação evidencia a necessidade de se definir o perfil de quem assume a coordenação entre parceiros. De certo modo, a coordenação depende de um "Eu". Se a existência das CLA e as suas competências são legalmente definidas, as diferentes CLA espalhadas pelo País representam realidades diferentes e reflectem a dinâmica das instituições locais bem como as características dos respectivos contextos.
\end{abstract}

Palavras-chave: política social; coordenação; rendimento mínimo garantido.

\section{Introdução}

Este artigo em como base um projecto transnacional promovido pela Fundação Europeia para a Melhoria das Condições de Vida e de Trabalho, sob o título "Coordination in activation policies of minimum income policies", no qual o CESIS participou, desenvolvendo a componente portuguesa ${ }^{1}$.

- estudo tinha como objectivo identificar e analisar os mecanismos de coordenação accionados no âmbito de medidas sociais activas. Procurando dar cumprimento a este objectivo, em Portugal o trabalho centrou-se na implementação do Rendimento Mínimo Garantido (RMG) e no funcionamento das suas Comissões Locais de Acompanhamento (CLA), enquanto estruturas de coordenação vertical e horizontal a nível local.

Realizado entre finais de 1999 e meados de 2000, o projecto assentou numa abordagem qualitativa com a realização, em Portugal, de cinco estudos de caso distribuídos pelas diferentes regiões do País, sendo eles: Matosinhos; Covilhã; Amadora; Ferreira do Alentejo e Vila Real de Santo António.
As cinco CLA analisadas situam-se, pois, em zonas urbanas de forte concentração populacional e de recursos, bem como em zonas rurais desertificadas; abrangem áreas do litoral e do interior; intervêm em contextos diferentes tendo em conta os actores e os problemas locais. Na sua composição, as CLA envolvidas são também elas distintas quer do ponto de vista da sua dimensão, quer tendo em conta os parceiros que nelas têm assento.

Para a sua concretização foram realizadas 84 entrevistas junto de vários actores: responsáveis políticos; elementos das estruturas de coordenação nacional e regional do RMG; pessoal técnico afecto às instituições presentes nas diferentes CLA; beneficiários.

\section{Coordenação: o que é?}

A questão da coordenação das políticas europeias no sentido do fortalecimento da coesão social e económica, não só entre países da União mas no seio dos mesmos, foi colocada no topo da agenda política dos 15 pela Cimeira de Lisboa, em Março de 2000.

\footnotetext{
* Socióloga. Investigadora do CESIS - Centro de Estudos para a Intervenção Social. Contacto: cesis@mail.telepac.pt.

' Neste estudo participaram, pelo CESIS, Ana Cardoso e Guida Ramos.
} 
Conceito que emerge com uma forte força política no final dos anos 90, a coordenação tem, no entanto, uma história que remonta ao início da década de 60 quando, nomeadamente nos Estados Unidos, surge o "Planned Programme Budgeting" que procurava organizar o governo central e local de forma a reduzir os efeitos de uma lógica funcional e departamental. No Reino Unido, nos anos 70, o "Joint Approach to Social Policy" procurava igualmente uma coordenação das políticas, quer a nível central, quer a nível local.

Também em Portugal, nos anos 60, se desenvolveram algumas experiências, em particular no âmbito do então Serviço de Promoção Social com o qual se preconizava uma noção de desenvolvimento enquanto actividade multidisciplinar que tomava a participação e a cooperação entre serviços e instituições como a filosofia central de trabalho.

A coordenação é, pois, um conceito, e uma prática, com história e que, ciclicamente, parece surgir como estratégia para a melhor prossecução de determinados objectivos das políticas estatais e, em particular, no que aqui diz respeito às políticas sociais.

Alguns autores afirmam a importância da coordenação nas políticas sociais fazendo depender dela a eficácia na luta contra a exclusão, sendo que a coordenação se deve estabelecer não só entre os vários domínios de intervenção da política social como entre os vários níveis de actuação (central, regional e local, actores públicos e privados).

É a multidimensionalidade da exclusão social que exige formas adequadas de coordenação, entendendo-se a coordenação como "the general principle that governs the design and implementation of social policies, which translates into specific actions undertaken by the government and which aim to increase the effectiveness of policy measures by preventing the duplication of actions, reducing the external social costs resulting from these interventions when they have different objectives and promoting the complementary nature of policy measures and social practices by all actors involved" (Pereirinha, 1993 in Pereirinha, 1999:29).

$\mathrm{Na}$ mesma perspectiva Geldof e Vranken (1999) afirmam que a diferenciação e a complexificação crescente das sociedades actuais contribuem para o ênfase dado à coordenação debatendo-se esta, permanentemente, entre o desejo de uma concepção holística dos problemas sociais e a cada vez maior dispersão das responsabilidades a este nível.
A coordenação é um termo utilizado numa variedade de formas e com diferentes significados. Geldof e Vranken discutem a coordenação em torno de duas dimensões (Geldof, Vranken, 1999: 15): a vertical e a horizontal, reconhecendo-se a existência de potenciais relações entre estas duas dimensões bem patentes, por exemplo, na descentralização dos serviços que, sendo um processo vertical, tem consequências inevitáveis ao nível da dimensão horizontal, implicando, pois, mais e melhor coordenação entre todos os actores envolvidos.

Assim, a primeira dimensão diz respeito às relações entre diferentes sectores da governação e à forma como os objectivos das políticas, concebidas a um nível central, são interpretados e implementados a um nível local. A segunda refere-se às relações entre organismos públicos e a sociedade civil e salienta a capacidade destes organismos assegurarem percursos integrados de inserção a populações em situação de exclusão.

Neste contexto, a coordenação situa-se a três níveis sendo possível, a partir daí, identificar os seus resultados.

Ao nível político, onde a análise dos resultados da coordenação se deve centrar no desenvolvimento de objectivos e na sua tradução num conjunto coerente de políticas, programas e medidas.

Ao nível das instituições, onde a coordenação deverá produzir um aumento da capacidade de oferta de serviços integrados; o seu enfoque deve situar-se na forma como as instituições se organizam nesse sentido.

E, finalmente, ao nível dos indivíduos, onde o enfoque deverá ser no surgimento de respostas e serviços que melhorem a situação das pessoas em situação de exclusão e que providenciem uma perspectiva para a inclusão através de trajectórias e percursos que, estando de acordo com as necessidades das pessoas, tenham em vista o desenvolvimento do seu capital social, cultural e económico.

Genericamente a coordenação é entendida como algo positivo derivando "from a conception of policy process as rational and ordered: coherent, consistent and inclusive with the aim of achieving efficiency and effectiveness. In turn, such an approach pre-supposes a disposition to co-operation rather than a competition or a conflit" (Ditch; Roberts, 2001: 34).

É neste sentido, e na sequência de Glennerster (1983), que aqueles autores distinguem entre uma perspectiva "optimista" e "pessimista" da coordenação. 
A "optimista" vê a coordenação como uma parte essencial do processo político implicando uma análise compreensiva e a implementação de mecanismos adequados. A "pessimista" entende a coordenação "as not only redundant but doomed, in so far as it cannot be planned or mandated by governments since the policy process consists individuals and organisations bargaining in the political market place" (Ditch, Roberts, 2001: 34).

Mesmo partindo de uma perspectiva mais "optimista" é genericamente aceite que, para existir uma efectiva coordenação, são necessários certos pré-requisitos. Pressman e Wildavsky (cit. in Ditch, Roberts, 2001: 34) referem-se à necessidade de uma consistência e coerência entre os objectivos e elementos de uma política ou projecto; entre um conjunto de políticas transversais por cuja implementação são responsáveis pela sua implementação diferentes organismos; essa mesma consistência e coerência devem estar presentes nas acções em que tais políticas se traduzem; e, finalmente, que os serviços prestados ao público revelem aquela natureza.

Sendo certo que a coordenação contraria, de certa forma, a lógica de funcionamento das instituições, quer públicas, quer privadas, em que medida o esforço para a sua efectivação será compensador? A este propósito, Geldof e Vranken propõem uma abordagem da coordenação a partir do local e salientam que o sucesso da coordenação passa pela garantia que as instituições dão aos seus beneficiários / utentes de "a coherent supply of services which improves their (financial, social personal and employability) situation and provides a real prospect for integration in collaboration with all relevant actors and institutions" (Geldof, Vranken, 1999: 20).

\section{A Coordenação em Portugal - O Pressuposto do Partenariado}

Em Portugal, o termo coordenação está subjacente a outros conceitos bem mais utilizados, na política social, sobretudo quando se analisa os princípios e orientações das práticas que a concretizam. Partenariado ou trabalho em parceria têm sido os termos mais utilizados para designar estruturas e modos, mais ou menos formalizados, de cooperação entre diferentes actores, com o objectivo de criar novas respostas, ou uma resposta concertada, face aos problemas emergentes e de contribuir para o desenvolvimento local.

A entrada de Portugal na então Comunidade Económica Europeia (em 1986) trouxe consigo a participação no Programa Europeu para a Integração Socioeconómica de Grupos Menos Favorecidos, genericamente designado Pobreza III, no qual o partenariado, como cooperação formal de pessoas e entidades, era um dos princípios orientadores da intervenção.

No contexto deste Programa, convocou-se e fez-se convergir "no campo da luta contra a Pobreza e Exclusão Social, o conjunto diverso (e até disperso e, por vezes, não desperto para tal problema) de agentes locais recobrindo a pluralidade de interesses, contributos e áreas de influência sociocultural, económica e política" (Vários, 1994: 16). Por outro lado, o carácter local destes projectos revelou-se facilitador de metodologias mais adequadas ao "conhecimento das estruturas e mecanismos de empobrecimento e exclusão social, a uma melhor compreensão sobre as razões da insuficiência ou desadequação das práticas estatais correntes (sectoriais e segmentadas) e sobre as potencialidades da experimentação de novos modelos de intervenção" (Vários, 1994: 20).

A prática de intervenção dos projectos desenvolvidos, em Portugal, ao abrigo do referido Programa, deu origem a experiências inovadoras demonstrativas das potencialidades do diálogo e da cooperação inter-institucional a nível local. Estas experiências marcaram, decisivamente, o quadro da assistência / acção social em Portugal e deram origem a organizações que ainda hoje permanecem. No entanto, já em 1991, quando foi criada a Direcção-Geral da Acção Social, ela "aparece associada a tendências que visavam uma (re)articulação da dimensão social com sectores económicos valorizando acções planeadas em contexto de contributos advindos do partenariado" (Rodrigues et al, 1998: 9). Quando se delinearam, então, as novas tendências da acção social, propôs-se a "valorização da acção coordenada - o partenariado", definido da seguinte forma: "Partenariado significa concertação interinstitucional e trabalho em rede. A complexidade e a inter-relação dos problemas sociais não se compadecem com a cultura funcionalista das organizações. É chegado o tempo de se criar uma cultura de partenariado, forma concertada e articulada de funcionamento, que tem por base o reconhecimento das complementariedades 
e co-responsabilidade das organizações, sejam públicas ou privadas" (Madeira, 1992 in Rodrigues, 1998:10).

Por outro lado, o conhecimento produzido e divulgado sobre as questões da pobreza e da exclusão social, com base no qual o carácter multidimensional destes fenómenos se revela com maior expressão, começou a exigir, cada vez mais, uma intervenção integrada e sistémica, onde o território se impõe, exigindo uma articulação entre todos aqueles que nessa área intervêm no (ou próximo do) problema.

É bom não esquecer, porém, que algumas das medidas políticas que se consubstanciam na colaboração interinstitucional só surgiram no contexto de mudança do quadro político, no qual a exclusão social e o seu combate assumem uma tónica dominante.

Com efeito, é a partir da segunda metade da década de 90 que se define um conjunto de programas e medidas que denotam um esforço de planeamento e de inovação das estruturas, com vista à tal coerência de objectivos, integração de respostas e à coordenação.

Ao nível das medidas que introduzem uma componente de planeamento saliente-se o Plano Nacional de Emprego, elaborado em 1998 que, no contexto da Estratégia Europeia para o Emprego, se assume como um instrumento integrador do objectivo emprego em diversas políticas sectoriais.

Mais recentemente, refira-se a concepção do Plano Nacional de Acção para a Inclusão (PNAI), surgido em Portugal, à semelhança do que se passa nos restantes países da União Europeia, a partir dos objectivos estratégicos para a Europa delineados na Cimeira de Lisboa. O PNAI, segundo os textos oficiais "permitirá articular as políticas pertinentes e os actores responsáveis" (IDS, Junho de 2001: 8.); "o PNAI não tem tanto a vocação de ser uma instância concentradora e gestora de recursos, os recursos do PNAI são, grosso modo, os recursos públicos disponíveis que mobilizamos para esta luta, uma vez que o que ele vai fazer é balizar a actuação de curto e médio prazo das instituições que tutelam estas áreas e, nesse sentido sim, condicionar a respectiva alocação de recursos" (Pedroso in IDS, 2001: 10). O PNAI assume-se, pois, como um instrumento de orientação estratégica e de coordenação de várias medidas e recursos com o objectivo de promover a luta contra a exclusão social.
Ao nível da inovação das estruturas, registe-se, no âmbito nacional, a criação da Comissão Nacional do Rendimento Mínimo que integra representantes dos Ministérios da Educação, Saúde, Trabalho e Solidariedade (Segurança Social), Justiça e da Secretaria de Estado da Habitação; no âmbito local, as Comissões Locais de Acompanhamento do Rendimento Mínimo Garantido.

Conjugando, de certa forma, a perspectiva do planeamento e da inovação das estruturas, surge o Programa Rede Social. Criado em 1997, por resolução do Conselho de Ministros, este Programa pretende "fomentar a formação de uma consciência colectiva e responsável dos diferentes problemas sociais que tenda a incentivar redes de apoio social integrado de âmbito local contribuindo, através da conjugação de esforços das entidades locais e nacionais envolvidas, para a cobertura equitativa do País em serviços e equipamentos sociais (Resolução do Conselho de Ministros n. ${ }^{\circ}$ 197/97).

A Rede Social inscreve-se, pois, no âmbito de uma política social que, na sua concepção, busca a potenciação da eficácia da intervenção local, a partir de uma articulação entre o que são prioridades globais e especificidades locais; um incentivo à mais valia das relações de cooperação entre organismos públicos e privados; uma progressiva territorialização da intervenção social.

Neste sentido, a Rede Social tem um âmbito de implementação local, ao nível do concelho, organizando-se a partir dos Conselhos Locais de Acção Social (CLAS), dinamizados pelas Câmaras Municipais e onde têm assento representantes das entidades particulares sem fins lucrativos e dos organismos locais da administração central. Compete ao CLAS, entre outros aspectos, a dinamização de Comissões Sociais de Freguesia e a elaboração de um Plano de Desenvolvimento Social (PDS), a partir da construção participada de um diagnóstico local dos problemas sociais.

Assentando em princípios como o da inserção, a Rede Social deve actuar no sentido do incremento de projectos de desenvolvimento local, inscritos nos respectivos PDS; apostando na coordenação e na cooperação progressiva entre parceiros, a Rede constitui-se como um "suporte da acção, permitindo criar sinergias entre os recursos e as competências existentes na comunidade" (Programa Piloto da Rede Social 1999/2000, Documento de Apoio). 
Embora de sinal positivo, a criação de todas estas novas estruturas locais de articulação interinstitucional, de fomento da consolidação de partenariados e de coordenação de acções, transporta consigo alguns riscos tendentes à produção de efeitos perversos, contrariando os princípios que as norteiam.

Com efeito, se pensarmos que às comissões locais aqui referidas acrescem outras, como as Comissões de Protecção de Crianças e Jovens em Perigo, por exemplo, vislumbra-se uma multiplicação excessiva deste tipo de estruturas que, em vez de contribuir para o dinamismo das instituições e para uma actuação planeada e concertada, pode dar origem a uma dispersão de esforços por parte dos/ as técnicos/as e para o sentimento agravado de uma actuação casuística orientada para a resposta às prioridades de cada uma destas estruturas. É neste mesmo sentido que o Conselho Económico e Social considera que "estas novas comissões e o seu funcionamento devem ser alvo de acompanhamento, incluindo, necessariamente, a avaliação externa, permitindo extrair ilações que possam ser úteis, quer para o seu desenvolvimento, quer para o de outras comissões que se criem" (CES, 1997:15).

\section{O Rendimento Mínimo Garantido e o Contexto da sua Implementação}

Numa sociedade em que as elevadas taxas de pobreza se assumem apenas como uma das formas de exclusão social, está-se perante um contexto onde um número significativo de indivíduos e grupos se encontram numa situação de não satisfação dos direitos de cidadania.

A cidadania dos tempos modernos constrói-se e consolida-se em torno de um conjunto, cada vez mais alargado, de direitos sociais (juntando-se, assim, aos direitos civis e políticos) mas a crise e as transformações recentes do Estado-Providência consubstanciam-se numa incapacidade de realização desses direitos. "A exclusão social, enquanto fenómeno actual de manifestação dessa crise, não só exige actuação política de garantia dos direitos sociais mas a sua própria redefinição ou extensão: o direito de integração como elemento para a reconstrução dos direitos de cidadania" (Pereirinha, 1999: 33).

Neste quadro, as políticas sociais jogam um papel importante ao nível da garantia da realização

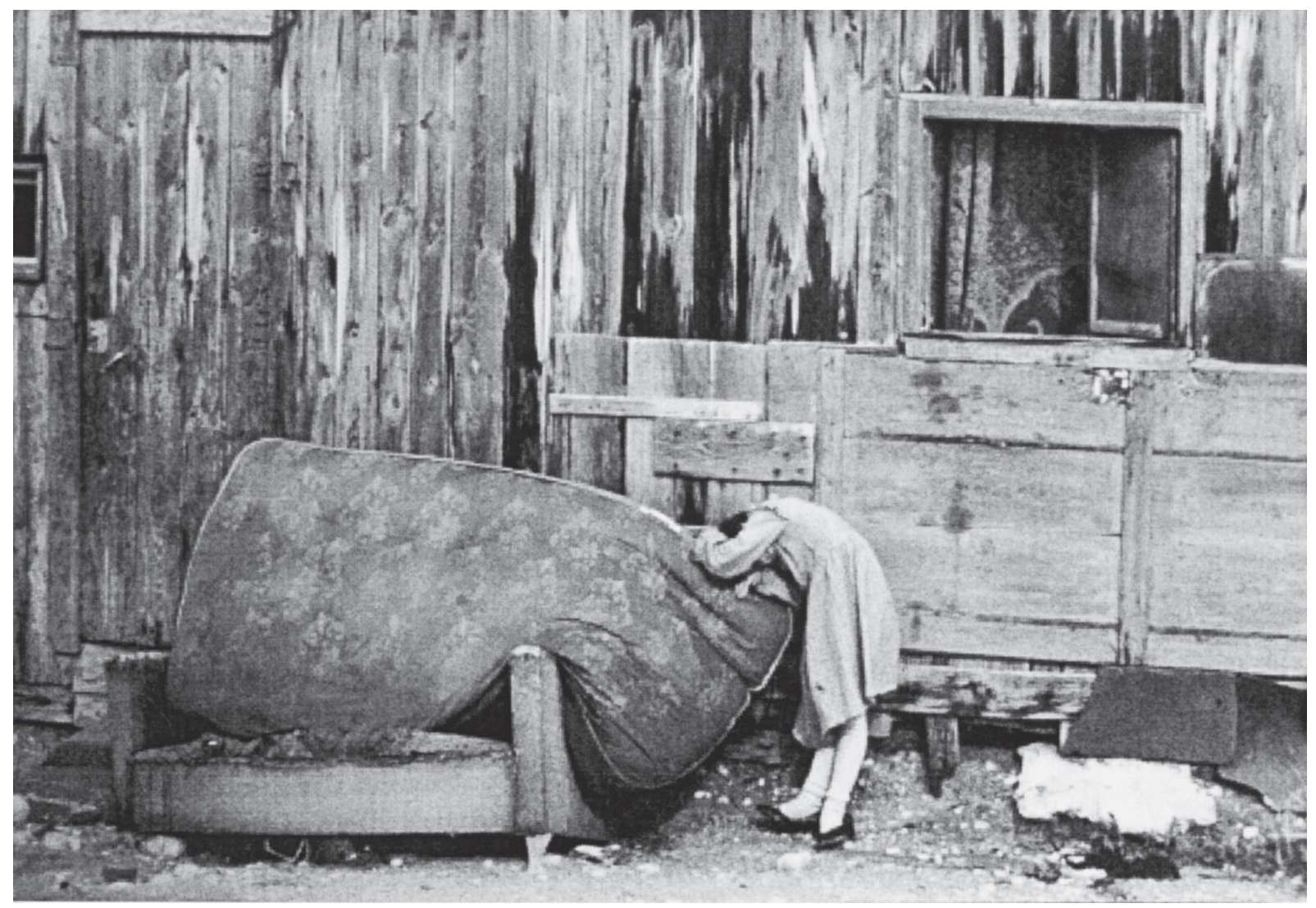

Foto de Isabel Guerra 
dos direitos e da promoção dos mesmos; na sua inter-relação com as políticas económicas, elas próprias condicionam ou determinam aspectos específicos de modelação dos mecanismos que actuam sobre o fenómeno da exclusão social.

O actual sistema de segurança social, enquanto direito consagrado a todos os cidadãos, é criado após a Revolução de Abril de 1974 mas é com a publicação da Lei de Bases da Segurança Social, em 1984, que são direito constitucional os princípios gerais da universalidade e da igualdade em que ainda hoje assenta o sistema. Até à criação da nova Lei de Bases em Agosto de 2000, o sistema de segurança social era composto por dois regimes: regime geral e regime não contributivo.

O regime não contributivo era completado com a acção social que, de acordo com a Lei de Bases de 1984, se destinava a prevenir situações de carência económica, disfunções e marginalização social e, simultaneamente, a promover a integração das referidas situações.

Correspondendo a uma evolução em termos conceptuais, o termo acção social substitui o de assistência social, pretendendo-se, com isso, reflectir uma mesma evolução ao nível da prática dos serviços. "Nesta perspectiva a assistência social traduz-se em acções de carácter terapêutico, parcelar e paternalista. A sua actuação visa dar resposta a situações de necessidade que afectam certos grupos, estritamente definidos, sem considerar as suas causas, sem considerar a participação dos indivíduos na resolução dos seus próprios problemas. Contrapondo-se a esta perspectiva, existe uma noção de acção social, cujos objectivos são a melhoria da qualidade de vida das pessoas e grupos pela harmonização das relações sociais." (Cardoso, 1993:141).

Existem, porém, alguns autores que defendem uma conceptualização de Assistência Social em ruptura com uma atitude assistencialista e com um cariz meramente emergencial da mesma, orientada para a complementação de lacunas e incumprimento de ramos vários da política social. Advoga-se, sim, uma política de assistência social claramente relacionada com uma noção ampla de protecção (que não só de acções) social, que responsabiliza o Estado e a colectividade: Defender a "especificidade da assistência social, resulta, ainda, de a reconhecer diferentemente de outras áreas da política, como potencial abrangente da globalidade das dimensões que dão corpo às necessidades humanas e sociais de viver e conviver (...). Também este aspecto a demarca de outras políticas cujo âmbito é geralmente circunscrito a uma dada área de necessidades. Só a dimensão política pode ser na assistência social a correspondente ao teor das exclusões geradas nas sociedades contemporâneas" (Rodrigues, 1999: 279).

A actuação da acção social situava-se a dois níveis: a prestação de serviços com a gestão directa de equipamentos sociais ou com o estabelecimento de acordos com instituições particulares de solidariedade social que asseguram essa gestão; a atribuição de subsídios a uma população que se dirige aos seus serviços de atendimento. Note-se que a atribuição de tais subsídios reveste-se de uma natureza totalmente discricionária, dependendo os montantes atribuídos das verbas disponíveis em cada região e no momento e, muito frequentemente, da apreciação subjectiva da(o) técnico(a) de serviço social que faz o atendimento. Este modo de actuação da acção social faz com que, pese embora a mudança de terminologia, permaneça uma tradição assistencialista que considera carências mas desconhece direitos.

Se a inclusão da acção social no âmbito da segurança social, a partir da referida Lei de Bases de 1984, foi considerada um passo legislativo importante na consolidação do carácter não supletivo de um Estado que se afirma comprometido com o domínio social, é certo que até à criação do Rendimento Mínimo Garantido, a acção social “manteve a gestão (de difícil gestão) de subsídios pecuniários e em espécie manifestamente insuficiente (...) e penalizadores das expectativas da população e dos profissionais encarregados dessa administração" (Rodrigues, 1999: 40).

Só no final dos anos 90, com o Rendimento Mínimo, se vem afirmar, no âmbito de acção social, um direito próximo aos observados nos regimes de segurança social. A criação do Rendimento Mínimo Garantido, em 1996, corresponde à única prestação associada à intervenção da acção social que estabelece um limite de rendimento abaixo do qual todos têm direito.

Abandona-se, assim, uma abordagem mais assistencialista e procura-se contrariar a tendência para uma "subsidiodependência" por parte da "população assistida". O novo desafio colocado à acção social foi o de co-responsabilizar os indivíduos, as diversas instituições e toda a sociedade na execução de um conjunto de medidas de intervenção 
participada, na qual cada actor assume determinados compromissos de cooperação, no sentido da definição de uma trajectória de inserção.

\section{O Conceito de Inserção}

O objectivo último de qualquer medida social activa deve ser a inserção social dos seus beneficiários. No caso do RMG a trajectória de inserção dos seus beneficiários é assegurada pela definição do programa de inserção.

Segundo o Artigo $3^{\circ}$ do Decreto-Lei que cria o Rendimento Mínimo Garantido, “o programa de inserção é o conjunto de acções cujos princípios são definidos pelos Ministérios da Solidariedade e Segurança Social e para a Qualificação e o Empre$\mathrm{go}^{2}$ e assumido localmente por acordo entre as comissões locais de acompanhamento (...), previstas na presente lei, e os titulares do direito a esta prestação, com vista à criação das condições para a progressiva inserção social destes e dos membros do seu agregado familiar".

Em primeiro lugar, importa definir o conceito de inserção, enquadrado na perspectiva do Rendimento Mínimo Garantido, enquanto processo que permite ao indivíduo a sua integração no meio social, facilitando-lhe o exercício dos direitos sociais com a finalidade de obter a sua autonomia social e económica.

A inserção assume uma lógica de política social activa, visando a definição de estratégias de integração sócio-económica dos beneficiários. Este processo deve ser entendido como bastante lato e abrangente, englobando um conjunto de áreas que não se esgotam no emprego, passando por outras medidas de combate à pobreza e à exclusão social, nomeadamente pela formação profissional, saúde, educação e alojamento, ou seja, áreas que efectivam a plena integração do indivíduo/agregado no meio em que está inserido. Tem-se, assim, em consideração a multidimensionalidade da exclusão social.

Se este cenário não é inédito na acção social em Portugal, ele apresenta-se hoje com uma dimensão, generalização e legitimidade novas. A introdução da figura do Programa de Inserção "desloca o centro da gravidade da acção de ajuda financeira assistencial para as tarefas de desenvolvimento assentes na procura de novas formas de articulação entre o económico e o social, no quadro das comunidades territoriais" (Branco, 1999:71).

O programa de inserção implica, ainda, uma lógica de contratualização entre o cidadão-beneficiário e a sociedade. Embora existissem já práticas deste tipo, elas assumiam, até aqui, um carácter pontual e informal. O RMG vem, assim, institucionalizar este procedimento reunindo numa mesma base o direito e o dever. Ao formalizar as acções contempladas no programa de inserção através da assinatura de um contrato entre a CLA e o/a beneficiário/a parte-se do princípio de que este/a se encontra excluído/a de determinados direitos sociais, sendo dever da sociedade facultar-lhe as oportunidades com vista à verificação de tais direitos. Este é, em si mesmo, um direito que assiste ao/à beneficiário/a que, por seu turno, tem o dever de se envolver activamente no seu processo de inserção.

Do sucesso dos programas de inserção depende largamente o sucesso da medida. Uma das conclusões do Seminário Europeu "Políticas e Instrumentos de Combate à Pobreza na União Europeia: a garantia de um rendimento mínimo" aponta no sentido dos limites dos programas perante as dificuldades em se encontrar um emprego estável, adequado e razoavelmente bem pago para os/as beneficiários/as do RMG. "O resultado é uma reduzida inserção dos beneficiários do Rendimento Mínimo em empregos do mercado regular de trabalho e a sua participação em actividades caracterizadas por uma grande precariedade e socialmente desqualificadas" (Hespanha, 2000:13). Também na avaliação da fase experimental do rendimento mínimo (vd. Capucha, 1998.) se chamava a atenção para o facto de o RMG poder produzir um efeito perverso ao contribuir para a manutenção de baixos níveis de remuneração do trabalho, com as consequências que daí advêm para a manutenção das taxas de pobreza.

\section{As Comissões Locais de Acompanha- mento do RMG - estruturas de coor- denação?}

\section{A retórica}

As Comissões Locais de Acompanhamento do Rendimento Mínimo Garantido são entendidas

\footnotetext{
De notar que, no XIV Governo Constitucional, a estrutura ministerial foi alterada, passando a medida para a tutela do Ministério do Trabalho e da
} Solidariedade. 
como condição determinante do sucesso da medida; "se as CLA não forem entidades operativas, há sérios riscos de que a medida possa ser empobrecida, reduzida a mera prestação pecuniária que, visando elevar a dignidade humana, resulta insuficiente para a inversão das trajectórias pessoais e sociais de exclusão. Daí ser fundamental que essas comissões possam ser agentes dinâmicos e capazes de pôr em comum recursos públicos e da sociedade civil tendentes à promoção da inserção social dos beneficiários do RMG" (CES, 1997: 13).

É a Lei $n^{\circ} 19$ - A/96 de 29 de Junho, que institui o Rendimento Mínimo Garantido, que prevê a criação das Comissões Locais de Acompanhamento. Estas Comissões têm um âmbito territorial que corresponde ao dos municípios (ou concelhos); caso os municípios tenham um elevado número de habitantes ou exista uma acentuada dispersão geográfica, que justifique a constituição de mais de uma CLA, na mesma área territorial, o Centro Regional de Segurança Social (ou o agora Centro Distrital de Solidariedade e Segurança Social) competente poderá fazê-lo, após audição das autarquias.

As CLA são compostas, obrigatoriamente, nos termos da referida lei, por: um representante da Segurança Social; um representante do Centro de Emprego; o coordenador Concelhio do Ensino Recorrente; um representante do Centro de Saúde.

A lei prevê, ainda, um conjunto de entidades que podem integrar as CLA desde que manifestem a sua disponibilidade para tal, exerçam a sua actividade na área geográfica da CLA; tenham a sua situação regularizada perante o fisco e a segurança social. Essas entidades são: as autarquias locais; as Instituições Particulares de Solidariedade Social (IPSS); as associações empresariais e sindicais; outras entidades sem fins lucrativos, legalmente constituídas.

Pela sua potencial composição, verifica-se que as CLA ultrapassam em muito uma coordenação entre a Segurança Social - na qual se inscreve o orçamento da prestação do Rendimento Mínimo Garantido e cujos serviços locais asseguram o atendimento à população e trabalham no sentido da realização dos programas de inserção - e as medidas de emprego e formação - implementadas, a nível local, pelos Centros de Emprego, e entendidas estas, frequentemente, como as que protagonizam o objectivo da inserção.
Com efeito, na medida em que abrangem, no que diz respeito a parceiros obrigatórios, os domínios de maior vulnerabilidade da pobreza, que passam também pela educação e pela saúde, e que, por outro lado, se prevê a inclusão de parceiros como autarquias e organizações particulares, as CLA apontam para a constituição de estruturas (complexas) transversais à sociedade e de optimização de recursos em diferentes vertentes de actuação das políticas sociais.

A criação das CLA inscreve-se, pois, nas tendências e desafios mais recentes da assistência / acção social, isto é, na territorialização, potenciando uma articulação entre a inserção de indivíduos e famílias e os processos de desenvolvimento local; na parceria e articulação entre diferentes instituições e entre vários sectores e políticas, numa óptica de promoção dos recursos necessários à inserção social e a um desenvolvimento integrado. Associadas ao Rendimento Mínimo Garantido, as CLA orientam-se, ainda, para a realização de um direito social.

Sem enjeitar as responsabilidades do Estado (instância consagradora de direitos cuja actuação a este nível se pretende reforçada, tal como refere Rodrigues,1998), a constituição das CLA acaba com o "monopólio" estatal ao nível da implementação das medidas de protecção social: outras entidades podem ser implicadas na própria coordenação local da CLA; outras entidades podem ser envolvidas, quer no atendimento directo à população, quer na elaboração dos relatórios sociais, definição de programas de inserção e respectivo acompanhamento.

Esta abertura permitida pela lei requer das/os técnicas/os de serviço social da Segurança Social uma postura profissional que implica a partilha de um "território" que até aqui era seu. Esta é também uma aprendizagem que deve ser feita, caso contrário, a medida será sempre entendida como "pertença" da segurança social, situando-se, aí, um obstáculo a uma efectiva coordenação.

Esta é, no entanto, uma questão que ultrapassa a dimensão local já que a níveis intermédios da coordenação, entre a Comissão Nacional e as CLA, a concepção da medida assenta numa imagem em que o ministério que tutela a segurança social personifica a medida - "são vocês é que pagam (...) o meu ministro nunca aparece a falar do 
$R M G$, é sempre o vosso 3 " - palavras de uma entrevistada funcionária do (então) Ministério do Trabalho e da Solidariedade dando conta das ideias de uma colega de outro ministério.

No discurso político as CLA surgem como um "forma participada de gestão de uma medida de política pública", não para que o "Estado delegue funções suas mas para que as possa cumprir com mais eficácia" (Pedroso in CES, 1997: 110). Procura-se alcançar tal eficácia através da optimização dos recursos existentes no sentido da promoção da inserção social dos beneficiários e, como tal, da sua autonomia face à medida.

Neste sentido, as "comissões locais não são apenas órgãos consultivos, são órgãos decisivos para promover a inserção dos cidadãos que dela beneficiam. Esta opção não foi acidental. O empenhamento da diversidade de agentes locais pode vir a contribuir decisivamente a curto, a médio, ou a longo prazo para que muitas famílias abandonem a situação de pobreza e exclusão que forçou o seu recurso ao rendimento mínimo" (Pedroso, in CES, 1997: 109).

No discurso político (a nível central) o Rendimento Mínimo Garantido assume, decisivamente, uma dimensão de direito. A sua inclusão como prestação da Segurança Social permite demarcar a medida de um apoio discricionário: "o facto de a medida ter essa característica de garantir um direito para poder fazer às necessidades, faz com que a responsabilidade de atribuir a prestação, neste caso a segurança social, tenha que se reger por critérios rigorosos" (Secretário de Estado da Segurança Social).

Esta concepção do RMG lança, pois, um desafio à sociedade, e às CLA em particular, no sentido de criar um "clima local de inserção" para o qual é indispensável a noção de que "o direito a um rendimento mínimo de subsistência é um direito que me assiste por eu existir, independentemente dos juízos de valor que façam sobre se mereço, ou não" (Secretário de Estado da Segurança Social).

\section{O que a coordenação torna visível}

Se, tal como foi referido anteriormente, na sua concepção, o RMG surge como um direito, como uma garantia de subsistência aos cidadãos de mais fracos recursos, este direito não é, no entanto, assumido como tal por todas as entidades com participação nas CLA, constituindo-se, localmente, como uma das razões mais frequentes de ruptura entre parceiros.

Ele constitui-se, ainda, como um factor de divergência entre o discurso político local e central, pesem embora as possíveis convergências político-partidárias entre ambas as esferas do poder. O que está em causa, por parte de alguns, é, de facto, a negação da consignação do RMG como um direito a que todos têm acesso, desde que se verifiquem as condições de recurso, relegando-se, para um segundo plano, as questões da inserção social. A isso está subjacente um desejo de manutenção do exercício de um certo controlo social, e do poder que este confere, que é retirado quando há critérios universais pré-definidos, sem lugar para uma apreciação subjectiva: “O que está em causa não é a inserção social, é saber se as pessoas merecem, ou não, o RMG” (Covilhã); “"Há ainda entidades que não vêem a medida como um direito, ainda é um favor que se está a fazer às pessoas" (Matosinhos); "Este merece o RMG, este não merece, é ainda muito uma questão que se coloca nas zonas rurais, onde se conhece toda a gente e, portanto lá se decidia. E, depois, há a questão partidária: "este é filiado no partido tal; esse não merece nada" (Covilhã).

Como é óbvio, as divergências partidárias, protagonizadas em diferenças de interesses, são, pelo menos em alguns locais, outro factor de clivagem e actuam, por vezes, como factor de bloqueio da parceria e de uma maior rentabilização dos recursos com vista à inserção dos beneficiários, prejudicando-se, assim, não só a imagem da medida mas os próprios beneficiários na sua trajectória de inserção. Cria-se como que uma espécie de círculo vicioso, já que a uma má imagem corresponde um menor investimento na medida, pois a mesma "não traz votos" (Ferreira do Alentejo).

Enquanto estrutura de coordenação, a actuar numa proximidade estreita com a realidade local, as CLA permitem uma grande visibilidade dessa mesma realidade nas suas diferentes dimensões. Os problemas da pobreza e da exclusão são agora expostos perante todos, mesmo perante aqueles que

\footnotetext{
${ }^{3}$ As frases em itálico são extractos das entrevistas realizadas no âmbito do estudo.
} 
tinham, até então, um maior distanciamento em relação aos mesmos contribuindo-se, desta forma, para a sua co-responsabilização - "Dantes, tudo o que tinha a ver com a pobreza era da responsabilidade da segurança social. Não havia uma tentativa de resolução dos problemas por parte das outras entidades porque também não havia uma compreensão correcta das situações. Neste momento, penso quem com todos os erros, com todas as dificuldades, o RMG tem sido muito positivo a este nível" (Covilhã).

Este aspecto pode dar origem a uma maior mobilização dos parceiros em torno do objectivo comum de erradicar (ou pelo menos de minimizar) a pobreza, promovendo um dinamismo reforçado e concertado ao nível da implementação de acções: "A Junta de Freguesia apresentou a candidatura ao Centro de Emprego para a contratação de pessoas e a Santa Casa da Misericórdia disponibilizou uma carrinha para o transporte dos documentos para o Centro Regional de Segurança Social" (Matosinhos); "O RMG trouxe o trabalho em parceria. Dantes, cada instituição actuava isoladamente, neste momento, há um trabalho mais articulado. Esta medida veio dinamizar e motivar os organismos públicos, e não só, a não quererem decidir as coisas sozinhos mas antes interligados" (Covilhã).

A CLA, enquanto estrutura criada do "topo para a base", gera dinâmicas locais e pode desencadear movimentos de pressão da "base para o topo". Este dinamismo, criado de facto em alguns contextos, e considerado como positivo, não deixa de ter os seus "custos". Com efeito, ele é muitas vezes percepcionado, por quem mais directamente o protagoniza, o pessoal técnico das instituições, como uma carga de trabalho adicional, mantida apenas pelo seu profissionalismo. Quando, porém, esse pessoal apresenta fragilidades no que diz respeito, por exemplo, ao seu vínculo contratual, uma tal dinâmica pode ser interrompida, com outro tipo de custos que daí certamente advêm.

A CLA possibilita, ainda, a visibilidade dos modos de agir e de intervir das instituições, o que pode criar protagonismos, nem sempre desejáveis, na base de uma actuação mais activa de certas instituições junto das populações desfavorecidas mas contribui, também, para uma maior "abertura" das organizações à troca de experiências e de metodologias, proporcionando-se, assim, também, maiores competências técnicas. "Muitas vezes à frente das associações temos determinadas pessoas, com determinados pensamentos e atitudes e com as quais temos que lidar e tentar contornar a situação. Por isso digo que nunca será por má vontade mas por razões de falta de experiência e de formação das pessoas, que levam algumas associações a estarem um pouco fechadas a este tipo de projectos" (Covilhã).

Porém, nem sempre esta abertura é isenta de conflitos, sobretudo quando uma intervenção mais activa, baseada numa metodologia que fomenta a participação e o "empowerment", se confronta com uma outra forma de actuar, pautada pela gestão de equipamentos e por uma assistência paternalista (ou maternalista, dada a forte presença, de mulheres nas instituições sociais), assente numa concepção da pobreza não como fenómeno social, mas como problema individual de grupos e famílias a quem faltam determinadas competências. Pode confrontar-se, ainda, com um modo de intervir muito pouco orientado para as necessidades dos grupos mais desfavorecidos da população: "temos algumas medidas (...) mas tem que haver determinadas entidades a candidatarem-se e isso é que não acontece. E não acontece, porque dizem que essas pessoas (os/as beneficiários/as do RMG) não interessam, faltam muito" (Covilhã).

O conflito poderá ser positivo se daí advir um crescente dinamismo e uma crescente adopção de métodos activos de trabalho, promotores do desenvolvimento pessoal e social das populações mais fragilizadas e, como tal, da sua inserção social.

No contexto português, o trabalho ao nível das CLA, mais do que um tradicionalismo no que diz respeito à actuação das instituições, põe em relevo a fragilidade da estrutura de pessoal de uma boa parte delas, o que, por seu turno, impõe limitações à actuação das instituições. Aí, o princípio da rentabilização de recursos humanos não é posto em causa; ele não chega sequer a ter lugar; tal como dizia um dos entrevistados "como se pode rentabilizar o que não existe?".

A falta de recursos humanos e a necessidade de mostrar resultados, tendo em conta que esta é uma medida de política alvo de críticas por parte

\footnotetext{
${ }^{4}$ Agora Centro Distrital de Solidariedade e Segurança Social.
} 
de um sector da opinião pública e de certos quadrantes políticos, exerce uma pressão sobre os serviços e o seu pessoal técnico e, em alguns casos, torna-se factor de bloqueio da acção e da própria coordenação. A articulação pretendida "desgasta-se" no trabalho que se devia realizar e não se consegue; a planificação perde-se nas urgências a que é preciso atender.

A visibilidade promovida pela medida cria a necessidade de, e obriga a, uma avaliação. Aqui, registam-se algumas resistências por parte do pessoal técnico. A avaliação, se entendida como necessária, por alguns, não só como técnica de medição de impactes mas como instrumento de produção de conhecimentos sobre a população-alvo e método para uma maior eficácia da acção, é, por outros, evitada, ou pelo menos não facilitada. O tempo que a avaliação retira à acção é um dos argumentos mais fortes para a sua não concretização; o "medo" da avaliação, e do que de questionamento das práticas de trabalho ela contempla, é uma questão latente mas não explicitada. É certo que, durante anos, a avaliação foi uma prática ausente dos serviços de acção social, públicos ou privados, e da política social, em geral. A avaliação, enquanto método de trabalho, foi introduzida pelos projectos europeus de luta contra a pobreza, tendo vindo a generalizar-se a outros programas, situando-se, no entanto, em acções delimitadas no tempo, orientadas por objectivos definidos. Urge, no entanto, fomentá-la sobretudo numa óptica de auto-avaliação em que todos os agentes são envolvidos num processo de reflexão permanente.

\section{Entre o discurso e a prática local}

Embora a estrutura das CLA e o seu modo de funcionamento sejam determinados por decreto-lei, elas constituem realidades muito diferentes entre si, espelhando, como se disse anteriormente, as dinâmicas das instituições locais e as características dos contextos em que estas se movem.

Há um conjunto de factores que influi no sentido de uma maior ou menor coordenação entre os parceiros da CLA, entre os quais se pode ressaltar: a (in)existência de experiências anteriores de trabalho em parceria; o carácter, prioritário ou não, que é atribuído ao RMG; as concepções em torno da pobreza e da exclusão social e da medida enquanto prestação de direito; uma maior ou menor capacidade de decisão por parte dos representantes das organizações na CLA; a maior ou menor abertura por parte das hierarquias dos serviços públicos de segurança social face à autonomia da CLA.

Existe, no entanto, um aspecto que parece sobressair entre todos os outros: o perfil da pessoa que dinamiza a CLA e a forma como esta interage com os representantes das outras instituições.

As parceria são feitas por, e entre, pessoas, muito mais do que por, e entre, entidades. Tal como afirmava uma entrevistada, "os parceiros são pessoas", daí que a coordenação não seja uma prática que se implemente "por decreto", já que ela "mexe" com formas de ser e agir dos indivíduos; daí, também, que a articulação entre duas entidades se faça, por vezes, de uma forma puramente informal, em que "basta um telefonema", "basta eu pedir..." para que qualquer questão se desbloqueie, mediante um procedimento que tem por base, única e exclusivamente, a boa relação entre duas pessoas. Em muitos casos, a coordenação depende de um "eu".

A capacidade de dinamizar e de mobilizar os parceiros em torno de um objectivo comum; a capacidade de negociar e de resolver conflitos; o domínio de um conjunto diversificado de conhecimentos na área social e económica; a capacidade de valorizar a experiência de cada um, evitando protagonismos exacerbados; a capacidade de tomar decisões estratégicas; a consciência da importância de um trabalho em comum; a capacidade de partilhar "territórios" e de não centralizar em demasia, são algumas das exigências que se colocam a quem está actualmente a coordenar as CLA do Rendimento Mínimo Garantido. Nestas exigências se jogam os novos desafios da acção social nos dias de hoje, implicando a construção de uma nova cultura profissional. A este nível, impõe-se uma formação contínua, dirigida às/aos trabalhadoras/es sociais, membros representantes na CLA e às/aos técnicas/os que realizam um trabalho directo com a população.

As práticas de coordenação exemplificadas através dos estudos de caso evidenciam a existência de três grandes tipos de coordenação.

Um, que se poderia chamar de uma coordenação de gestão centralizada com fraca capacidade de decisão, ilustrada pelo caso da Amadora.

A estrutura hierarquizada e burocratizada dos serviços de segurança social não facilita a autonomia da CLA e, por parte da coordenação desta, há o desgaste que decorre deste tipo de procedimentos - “A CLA é uma estrutura muito burocrática. É pre- 
ciso um programa, vai para Sintra, depois vem de Sintra e isso cansa-nos".

Também por parte das outras entidades parceiras, pouca autonomia é dada aos representantes na CLA e persiste uma forte concentração do poder de decisão "Quem está na CLA não tem poder de decisão. Os parceiros são representados pelos técnicos que são dependentes da sua instituição e não podem decidir".

É uma estrutura pesada, na sua dimensão, e bloqueada quer pelos problemas existentes ao nível do contexto local da sua intervenção quer pelos seus problemas internos, sem capacidade para delinear e implementar estratégias de solução: " $t e$ mos mais chorado as nossas incapacidades do que propriamente encontrado soluções. Na CLA apresentam-se constantemente os bloqueios e o que sinto é que são poucos os que foram banidos".

A articulação entre os parceiros limita-se, aqui, a uma simples troca de informações, o que acaba por ser desmotivante. A medida não é considerada como uma prioridade na sua actuação, pelo que as entidades com representação na CLA esperam mais do que contribuem para a efectivação da parceria.

Não existe uma cultura de parceria e, mesmo que as relações entre as pessoas sejam cordiais, e não tensas, cada um tem uma visão limitada da realidade, situada no seu próprio contexto, querendo, antes de mais, uma resposta aos interesses dos quais se sente representante: "A questão das parcerias não é clara para toda a gente. A cultura da parceria existe muito em termos teóricos porque em termos práticos as pessoas não assumiram bem. $O$ que eu noto na CLA é que muitos parceiros ainda acham que o RMG é do CRSS, e é o CRSS que tem que resolver o problema".

A prestação como um direito é minimizada pelos impactes negativos de um insuficiente trabalho ao nível da inserção revelado por um elevado número de processos sem a contratualização do programa de inserção e consequência de uma insuficiente afectação de recursos humanos: "os serviços não estão estruturados para uma medida em que se tem que atribuir uma prestação, fazer um programa e o respectivo acompanhamento (...) são poucos técnicos que estão em exclusivo na medida (...) teríamos que ter o dobro das pessoas" (parceiro - segurança social); "Não houve contratação de mais pessoal, há mais trabalho, um acumular de reuniões, não houve aumento das verbas, nem do apoio logístico. Tudo continuou a ser o mesmo que antes do $R M G^{\prime \prime}$ (parceiro - educação).

A exclusão é vista, não como um fenómeno social mas como um problema criado por certos indivíduos ou grupos, radicando neles a explicação para a existência de tal fenómeno; e o trabalho que é feito ao nível da inserção acaba por reforçar esta ideia, imputando-se, ainda, aos próprios, o não entendimento do programa de inserção e da contratualização a ele associada.

Um segundo tipo é o de uma coordenação dinâmica, que proporciona a partilha de responsabilidade e toma as suas próprias opções (veja-se o caso de Matosinhos e de Vila Real de Santo António).

Apesar dos problemas, verifica-se, em ambos os casos, a busca das melhores estratégias que visam a solução dos problemas existentes e que passa por uma implicação cada vez maior de todos os parceiros. A articulação entre as diferentes entidades ultrapassa, em muito, a simples troca de informações, sabe definir objectivos e planear acções o que significa boas possibilidades de se criar um efectivo clima de inserção já que os problemas associados aos/às beneficiários/as do RMG são discutidos como parte integrante dos problemas locais: "é a primeira vez que instituições públicas e privadas se sentam todas à volta de uma mesa para discutir os problemas locais, não só sobre os beneficiários do RMG mas sobre os problemas da região, como por exemplo, os do emprego e da qualificação profissional" (Vila Real de Santo António). É, pois, a acção social a funcionar numa óptica de desenvolvimento local, processo no qual a coordenação entre parceiros assume um papel central.

A medida é uma prioridade em torno da qual se rentabilizam recursos, se dinamizam localmente as medidas de política e se criam novas respostas. A luta contra a exclusão é entendida com uma tarefa colectiva, na qual todos têm o dever de participar e, neste caso, a prestação é assumida como um direito e as instituições assumem a sua função de solidariedade social.

"Todas as instituições, quer públicas, quer privadas, demonstram um máximo de esforço no sentido de proporcionar resultados a esta medida" (Vila Real de Santo António);

"Quando tenho reuniões a nível regional, muitas vezes coloco problemas que têm que ver com situações concretas do RMG e os meus colegas perguntam: mas tu vais a todas as reuniões do RMG? 
Eu só vou de vez em quando. Tu vais lá sempre? Eu mando ofícios" (parceiro-educação, Matosinhos);

"As instituições têm que crescer e acompanhar as medidas lançadas, porque estão a trabalhar para a população; se não acompanharem, deixam de ser instituições de solidariedade social" (parceiro Santa Casa da Misericórdia, Vila Real de Santo António).

Em ambos os casos os parceiros vão construindo uma cultura de parceria partindo, no entanto, de situações diferentes.

Em Matosinhos, este processo é facilitado por uma experiência anterior: "os técnicos já têm certas dinâmicas interiorizadas, é mais fácil (...). O trabalho em parceria anterior fez perceber as potencialidades deste tipo de funcionamento. Os parceiros já têm uma experiência anterior, articulamse melhor, de forma mais simples" (Matosinhos).

Em Vila Real de Santo António foi o Rendimento Mínimo, e a sua organização em comissões locais, que ajudou a que as instituições encontrassem objectivos comuns sem que, no entanto, fossem criados protagonismos inibidores de uma participação aberta a todos: "as instituições trabalhavam um pouco por si sós. Havia poucas reuniões e muitas vezes elas eram parcelares, entre a Misericórdia e a Câmara ou com alguma Junta de Freguesia. Não se tinha um objectivo comum como há no RMG, nem se envolvia tantas pessoas $e$ instituições." (Vila Real de Santo António); “É um caso curioso, porque não tem havido situações de protagonismo. Tem havido um espírito de humildade, de estar desinteressadamente, sem "colher louros", e as coisas têm funcionado bem" (Vila Real de Santo António).

O terceiro tipo é o de uma coordenação em ruptura, devido às fortes divergências entre os parceiros, em que a um núcleo dinâmico se opõe um grupo mais alargado de parceiros para os quais a medida não é prioridade nem lhe é reconhecido interesse (Covilhã e Ferreira do Alentejo), ficando por apurar em que sentido se irá orientar a actuação futura.

Numa destas CLA (Covilhã), a sua estrutura complexa, quer do ponto de vista da dimensão (58 entidades), quer da diversidade de interesses que move os parceiros reflecte-se sobremaneira no funcionamento da Comissão. Em qualquer um dos casos, porém, identificam-se claras e diferentes motivações onde o objectivo da inserção dos bene- ficiários não é de todo comum. Assim, é possível distinguir os que pertencem à CLA por razões de controle (político); os parceiros passivos que estão lá "porque foram convidados"; os parceiros activos movidos pela luta contra a exclusão social e que, se na Covilhã se restringe praticamente aos parceiros obrigatórios, em Ferreira do Alentejo conta com a participação de entidades privadas sem fins lucrativos.

Apesar de, em ambas as situações, terem existido experiências anteriores de trabalho em parceria, por via da existência de projectos de luta contra a pobreza, as mesmas não foram suficientemente positivas para serem rentabilizadas no âmbito do RMG havendo, pois, todo um trabalho a construir no sentido da partilha de objectivos comuns e de inverter a lógica do proveito individual: "tive exemplos de reuniões de parceria do projecto de luta contra a pobreza em que as pessoas vinham para discutir que dinheiro ia para esta freguesia e para aquela e quem saía mais beneficiado e bem visto aos olhos dos munícipes" (Ferreira do Alentejo).

A tenacidade de um núcleo faz-se sentir na busca e experimentação de várias estratégias para a motivação dos diferentes parceiros - "nós tentamos de várias maneiras e vamos continuar a tentar" (Ferreira do Alentejo) - mas reclama-se tempo para a construção de uma cultura de parceria: "O envolvimento dos agentes no processo requer tempo; é um processo gradual e não podemos esperar que os parceiros estejam sempre disponíveis (...). É preciso o envolvimento num projecto comum e aí ainda não há cultura amadurecida" (Ferreira do Alentejo).

De uma forma muito marcada, nestas CLA, surge a negação da medida como um direito a que todos podem ter acesso desde que satisfaçam as condições de recurso, dizendo-se, pois, que a mesma "não devia ser generalizada a todos os grupos" (Ferreira do Alentejo) e onde a inserção também não é vista como um direito das populações mas como dever de alguns: "as pessoas do $R M G$ deveriam, vá lá, não ser obrigadas mas quase, a participarem nas autarquias locais" (Covilhã).

Nesta perspectiva, torna-se mais fácil haver uma certa desresponsabilização de alguns parceiros no processo de inserção dos beneficiários: "há entidades que são capazes de não contribuírem muito para a sua integração (dos beneficiários do RMG) porque dizem que são pessoas problemáticas, sem condições" (Covilhã). 


\section{Os Impactes nos Beneficiários}

Em qualquer um dos casos é possível identificar efeitos positivos na vida dos beneficiários do RMG na sequência da sua participação na medida e, muito concretamente, de uma abordagem multidimensional dos problemas que afectam estas pessoas.

Os impactes do RMG na vida dos beneficiários situam-se, fundamentalmente, a dois níveis: na melhoria das condições de vida; no aumento da auto-estima, o que favorece a continuidade dos percursos de inserção.

No que diz respeito à melhoria das condições de vida, ela manifesta-se nos benefícios produzidos directamente pela prestação em si mesmo: diminuição das situações de endividamento; maior nível de satisfação das necessidades básicas.

Faz-se, ainda, sentir através das acções dos programas de inserção, manifestando-se, a este nível, os efeitos de uma actuação multidimensional assente num trabalho em parceria no âmbito das CLA. Essas acções têm contribuindo, especialmente, para a obtenção de melhores condições de habitabilidade e melhores níveis de saúde.

No que diz respeito à saúde, essa melhoria é conseguida através de um acesso facilitado aos serviços, nomeadamente a consultas de especialidade, e de uma maior cobertura dos cuidados médicos, em geral. A CLA tem aqui um papel determinante, funcionando como veículo de facilitação daquele acesso, seja através de uma discriminação positiva, seja através da identificação, dentro dos serviços, de pessoal técnico capaz de encaminhar e orientar os utentes e, sobretudo, de criar um clima que facilite o seu acolhimento. Não deixa de ser curioso que, sendo a saúde um direito constitucionalmente garantido, existam populações para as quais esse direito não está assegurado, devido ao tipo de atendimento, pouco inclusivo, que se verifica nos serviços locais.

No que se refere a um aumento da auto-estima, ele é concomitante com o aumento das qualificações escolares e profissionais desta população. Com efeito, para além da importância que a qualificação tem em termos de uma melhor inserção profissional, através da formação, os beneficiários adquirem competências sociais e pessoais que os tornam mais capazes de iniciar um percurso que contrarie a dependência.
Com efeito, não se verifica, na maior parte dos casos entrevistados, uma cultura de dependência em relação à prestação: "o $R M G$ é uma forma das pessoas não se acomodarem. O RMG não é uma reforma e, logicamente, as pessoas devem integrar- se na sociedade" (beneficiária - Covilhã). Na generalidade, há uma boa compreensão e aceitação das suas responsabilidades e a integração numa actividade profissional é encarada positivamente: “(...) porque afinal o que é isso de se inserir na sociedade? É ter a sua vida, a sua casa, o seu carro, a sua família, a sua independência, a sua satisfação pessoal, e para isso é preciso ter-se uma profissão" (beneficiária - Amadora).

Em certos casos, verifica-se uma maior participação das pessoas beneficiárias na definição dos programas do que noutros e, aqui, mais do que o tipo de coordenação e desempenho da CLA, influi o método de trabalho do próprio trabalhador/a social que, de uma forma mais directa, se relaciona com o/a beneficiário/a.

O fomento da participação dos/as beneficiários/as nem sempre é isento de conflitos que passam, antes de mais, por saber colocar ao mesmo nível duas posições que à partida são diferentes e que estão ainda muito marcadas pela ideia de "quem pede" e "quem dá". Se o RMG, enquanto direito, pretende anular esta ideia, nem sempre essa anulação é alcançada, tanto para a/o técnica/o, que continua, assim a exercer um poder sobre..., como para o/a beneficiário/a , a quem uma condição de pobreza prolongada e de grande privação conduz a uma posição de submissão.

Em contrapartida, estabelecer a prestação pecuniária e associar-lhe o direito à inserção é promover, junto de certos grupos, uma atitude reivindicativa que nem sempre é bem acolhida pelas/os técnicas/os, pelo que algumas/uns delas/es constroem uma imagem negativa, da medida.

Em algumas CLA, optou-se por uma presença dos/as beneficiários/as no núcleo, provocando-se uma maior aproximação entre estes/as e todos os parceiros e, como tal, um conhecimento da situação que é por todos partilhado; um maior conhecimento do funcionamento da medida e da CLA e uma tomada de consciência, por parte dos/as beneficiários/as, relativamente a um compromisso que é assumido em conjunto - beneficiário/a e sociedade. Esta presença dos/as beneficiários/as no núcleo, embora promotora de participação, envolve, contudo, alguns cuidados já que pode funcionar 
também como promotora de uma forte inibição das pessoas que não dispõem ainda de capacidade de negociação, num contexto ainda marcado por uma desigualdade de papéis.

A abordagem feita, no âmbito do RMG, ao nível da inserção, afigura-se multidimensional. Não há dúvida que essa multidimensionalidade é possível através da utilização de uma metodologia que assenta numa óptica de trabalho de projecto mas é, sobretudo, proporcionada pela presença de parceiros das diferentes áreas. Permite-se, assim, por vezes, que a partir de um único problema identificado, sejam detectadas outras carências e estabelecido um conjunto de relações entre os diferentes problemas-causas da pobreza. Desta forma, os percursos de inserção tornam-se, também, mais consistentes e coerentes.

Nos vários casos entrevistados, há uma múltipla intervenção abrangendo diferentes áreas: habitação, quando as casas não apresentam as condições mínimas; educação, quando o titular ou algum membro da família não tem, pelo menos, os níveis de escolaridade básicos; ou, ainda, integração em equipamentos, no caso das crianças; formação ou emprego com vista a uma inserção profissional; acompanhamento médico em situações de doença.

Apesar deste tipo de abordagem indiscutivelmente positiva, o processo de inserção dos/as beneficiários/as está altamente dependente de dois factores: tempo e recursos.

Tempo para que se concretize a inserção, o que implica muitas vezes, não só um processo de formação escolar ou profissional, mas também um processo de transformação pessoal (o que implica trabalhar com vista à autonomia). Tempo porque a inserção está muito dependente da situação de partida dos indivíduos e famílias, havendo sempre que ter isso em consideração: "claro que este projecto não pode ter $100 \%$ de sucesso, trata-se de uma conquista gradual, porque são famílias que viveram afastadas da própria convivência em sociedade durante muitos anos, portanto torna-se difícil fazer este trabalho" (Vila Real de Santo António).

No que diz respeito aos recursos, trata-se de recursos humanos para trabalhar a inserção dos beneficiários e de respostas (equipamentos sociais, acções, programas) para a concretização dos planos de inserção.

Quanto aos recursos humanos verificou-se em quase todos os estudos de caso, uma discrepância entre as necessidades manifestas e os recursos existentes, sendo esta uma das principais lacunas identificadas por diferentes actores no que diz respeito ao RMG. Esta lacuna tem efeitos perversos a vários níveis. Ao provocar o acumular de processos deferidos sem contrato, nem programa de inserção, dá origem a que situações que requerem uma intervenção imediata se percam e que, por outro lado, se crie uma noção contrária aquilo que é preconizado, ou seja, a de um direito-dever de inserção, onde a vertente do dever se anula. Os beneficiários demarcam-se em relação ao dever e pode fomentar-se uma cultura de dependência; gera-se, na opinião pública, um imagem negativa da medida e dos grupos de população que mais protagonizam essa ausência do dever, sendo-lhes imputadas responsabilidades, por isso mesmo, e aumentando a estigmatização social destes grupos. Contudo tais grupos apenas actuam nas brechas que o próprio sistema cria.

Importa, no entanto, salientar que mais do que uma insuficiência de recursos humanos se verifica a necessidade urgente de os serviços (públicos e privados) organizarem efectivamente o seu trabalho no sentido da inserção o que significa uma cultura de parceria e de coordenação e, como tal, também de planeamento e avaliação. Neste processo devem estar envolvidos não só as/os técnicas/os que trabalham directamente com as populações mas toda a organização: "a parceria implica mudanças de actuação e devia implicar mudanças na estrutura das organizações e às vezes é complicado mexer nelas. Penso que as pessoas estão sensibilizadas para tal mas é preciso tempo para resolver questões que implicam, alterações de coisas que há anos que funcionam nos mesmos moldes, sem grande abertura, sem grande flexibilidade. Alterar alguns procedimentos, significa alterar desde o director ao pessoal técnico, todos têm que estar envolvidos" (Matosinhos).

\section{Conclusões}

A coordenação não tem sido tema de análise da investigação em Portugal e, mesmo no discurso técnico, a coordenação dilui-se noutros conceitos bem mais utilizados. Com efeito, partenariado ou trabalho em parceria têm sido os termos mais utilizados para designar estruturas e modos, mais ou menos formalizados, de cooperação entre diferentes 
actores, com o objectivo de criar novas respostas, ou de uma resposta concertada, face a problemas sociais emergentes.

Contudo, o termo coordenação está cada vez mais presente no discurso político. Seguindo uma tendência que se faz sentir a nível europeu, o Rendimento Mínimo Garantido é acompanhado pela criação das Comissões Locais de Acompanhamento, surgindo, em paralelo, outras estruturas de base territorial tendo como objectivo a coordenação de acções e a cooperação entre diferentes entidades locais.

Orientadas por princípios positivos, estas estruturas podem correr o risco da sua excessiva multiplicação e da desmotivação face à participação por parte dos agentes locais. Por outro lado, para que tais estruturas, e em particular as CLA do RMG, atinjam a sua finalidade última não deve deixar de se considerar que:

\section{Bibliografia}

AAVV (1994), Pobreza é Com Todos, Lisboa, Comissão das Comunidades Europeias.

BRANCO, F. (1999), Acção Social em Debate, Lisboa, Direcção Geral de Acção Social.

CAPUCHA, L.(1998), Rendimento Mínimo Garantido: Avaliação da Fase Experimental, Lisboa, DEPP - Departamento de Estudos, Prospectiva e Planeamento do Ministério do Trabalho e da Solidariedade.

CARDOSO, A.(1993), A Outra Face da Cidade - A pobreza em bairros degradados de Lisboa, Lisboa, Câmara Municipal de Lisboa.

CONSELHO ECONÓMICO E SOCIAL (1997), Pareceres sobre o Rendimento Mínimo Garantido, Lisboa, CES, 1997.

DITCH, J. e ROBERTS, E. (2001), Activation, Concepts, Contexts and Pratice: establishing effective co-ordination, EFILWC, no prelo.

HESPANHA, P. (2000), "Síntese do Seminário", Seminário Europeu Políticas e Instrumentos de Combate à Pobreza na
- A coordenação não se concretiza "por decreto";

- A coordenação é um processo em permanente construção que pode causar problemas e conflitos entre actores;

- A coordenação precisa de tempo. Tempo para se concretizar; tempo para atingir os seus próprios objectivos e alcançar resultados;

- A coordenação implica a necessidade de uma avaliação constante;

- A coordenação não é possível sem os recursos humanos adequados. Importa salientar que não está em causa apenas a "quantidade" dos recursos afectos a este processo mas, em particular, o perfil de quem o dinamiza, levando à afirmação de que, ao nível local, a coordenação depende de um "Eu".

União Europeia: a garantia de um Rendimento Mínimo, Lisboa, IDS.

GELDOF, D. e VRAKEN, J. (sd), Integrated approaches to active welfare and employment policies, Relatório Final para a European Foundation for the Improvement of Living and Working Conditions.

IDS - MINISTÉRIO DO TRABALHO E DA SOLIDARIEDADE (2000), Políticas Sociais Activas em Portugal, Lisboa, IDS.

IDS (ed) (2001), "Plano Nacional de Acção para a Inclusão", Pretextos, n ${ }^{\circ} 5$.

RODRIGUES, F. et al (1998), Entre Parceria e Partenariado, Oeiras, Celta.

RODRIGUES, F. (1999), Assistência Social e Políticas Sociais em Portugal, Lisboa, Departamento Editorial do ISSScoop e Centro Português de História e Investigação em Trabalho Social.

PEREIRINHA, J. (coord) (1999), Exclusão Social em Portugal - Estudo de situações e processos e avaliação das políticas sociais, CISEP / CESIS. 